\title{
A África na ordem internacional do século XXI: mudanças epidérmicas ou ensaios de autonomia decisória?
}

\author{
África in the 21th century's international order: epidermic \\ changes or essays of decisory autonomy?
}

JOSÉ FLÁVIO SOMBRA SARAIVA*

Rev. Bras. Polít. Int. 51 (1): 87-104 [2008]

\section{Introdução}

O objetivo do presente artigo é o de suscitar novos conceitos acerca do lugar da África na ordem internacional que se desenha no início do século XXI. ${ }^{1}$ Merecerão destaque as atuais formas de inserção internacional dos seus Estados nacionais, criadas de dentro para fora das soberanias africanas, bem como o envolvimento crescente de antigos e novos atores globais que participam, de forma interessada e crescente, na gestação do futuro daquele continente. ${ }^{2}$

A hipótese aqui examinada é a de que o continente africano assiste transição positiva para um novo patamar de inserção internacional no início do novo século. Três conceitos centrais alimentam o exame dessa hipótese: a) o avanço gradual dos processos de democratização dos regimes políticos e a contenção dos conflitos armados; b) o crescimento econômico associado à performances macroeconômicas satisfatórias e alicerçadas na responsabilidade fiscal e preocupação social; e c) a elevação da autoconfiança das elites por meio de novas formas de renascimentos culturais e políticos.

\footnotetext{
* Professor do Instituto de Relaçôes Internacionais da Universidade de Brasília - iREL-UnB e diretor-geral do Instituto Brasileiro de_Relações Internacionais - IBRI (fsaraiva@unb.br).

1 Há nesse tópico duas linhas de interpretação que disputam hegemonia acadêmica acerca do novo papel da África no sistema internacional pós-Guerra Fria. Os que advogam em favor da adaptação sem mudanças insistem na idéia de certa reforma epidérmica, quase apenas cosmética do continente ante os novos desafios internacionais. Há a linha, na qual se inscreve este autor, que procura avaliar a hipótese de que há uma oportunidade de inserção mais altaneira, menos deprimida, da África no sistema internacional.

2 Pululam, na imprensa brasileira, interpretaçōes catastróficas das crises políticas africanas, como aquelas advindas do Darfur, os problemas políticos advindos das eleiçôes presidências em tradicional democracia africana como a do Quênia, ou dos problemas do Zimbábue. Ver, por exemplo, as avaliaçōes alarmistas produzidas nas primeiros meses de 2008 em grandes jornais nacionais: Mariana Della Barba, "Cinco anos de inferno em Darfour", O Estado de São Paulo, 6 de abril de 2008, p. A24; Elias Thomé Saliba, "Se os crocodilos falassem... O jornalista Peter Godwin vale-se de poderosa lenda africana para analisar a tragédia do Zimbábue”, O Estado de São Paulo, 6 de abril de 2008, p. D5. Quando não se reproduzem, na imprensa nacional, interpretaçōes de autores das exmetrópoles, algumas saudosas do passado colonial, criam-se imagens de eterno e cíclico desterro das sociedades e Estados africanos contemporâneos.
} 
Os argumentos centrais estão organizados em torno de quatro unidades. $\mathrm{Na}$ primeira apresentam-se argumentos que comprovam a elevação do status na África no mundo e o paradoxo da baixa apreciação, no Brasil, do novo lugar da África na sociedade internacional. Em segundo lugar, abordam-se alguns dos desafios das cinco décadas da formação dos Estados independentes da África. Em terceiro lugar, tratam-se algumas visōes depreciativas e positivas disponíveis na literatura universal acerca do papel da África no sistema internacional contemporâneo bem como os movimentos estratégicos de grandes Estados globais no coração do continente nos dias atuais. Em quarto avalia-se, no contexto dos países de língua portuguesa na África, a elevação gradual de status de Moçambique, caso emblemático da elevação da autonomia decisória na ordem internacional em construção no início do século XXI. À guisa de conclusão, avaliam-se iniciativas de soberania política na África que não são tributárias de criações políticas e econômicas de fora para dentro.

\section{A África na ordem internacional do início do século XXI: conceitos enviesados e necessidade de construção de novos parâmetros de análise}

A ordem internacional que se desenha no século XXI faz do mosaico africano uma necessidade umbilical da sua configuração. Há uma fronteira mundial cuja linha demarcatória está no triângulo africano de mais de trinta milhôes de quilômetros quadrados.

A África subsaariana, ou África negra, considerada a região mais pobre do mundo, cresce entre 5\% e 6\% ao ano desde $2003 .{ }^{3}$ Adaptações macroeconômicas à globalização moveram as economias de todo o continente para equilíbrios na área da gestão dos negócios dos Estados. Alvissareiras são a inflações médias, contidas na faixa de $6 \%$ desde 2003 , e as exportações que avançam, em 2006 e 2007, na proporção de $43 \%$ a $45 \%$ do PIB. Reformas econômicas liberalizantes e redução de vulnerabilidades externas geradas por saldos exportadores e crescente atração de investimentos externos diretos são fatos, entre outros, celebrados como de sinalização de sustentabilidade econômica pelos africanos e que ainda surpreendem aos elaboradores dos relatórios das agências internacionais, como o Fundo Monetário Internacional e o Banco Mundial. ${ }^{4}$

Há razôes para otimismo em todas as regiōes da África. O ambiente anima a confiança dos mercados. Na média da África negra, os investimentos internos equivalem a 19,4\% do PIB, percentual muito próximo do Brasil, embora

3 Segundo dados de hoje do Fundo Monetário Internacional, o PIB da região cresceu de 4\% em 2003, para 5,7\% em 2004, 5,6\% em 2005, 4,8\% em 2006, com previsão de crescimento em torno de 6\% para 2007. O crescimento da África foi no período mencionado, portanto, na média da América Latina e superior à média brasileira.

4 IMF \& BIRD, Africa Foreign Investment Survey 2006. Washington: IMF, 2007. 
considerado baixo para a sustentabilidade do crescimento econômico. $\mathrm{O}$ vetor da elevação do crescimento interno é visível desde 2002 e tende a crescer nos próximos anos, mesmo ante a crise financeira que se desenha no contexto do capitalismo norte-americano. A África vem sendo escolhida como parte das prioridades para novas áreas e carteiras de empréstimos do Banco Mundial.

Há preocupaçōes, no entanto, no campo social, que variam de país a país, por meio de políticas de construção de metas de redução da pobreza. Há também a atenção dos setores financeiros em alguns países africanos com a eventualidade de um novo ciclo de endividamento interno advindo principalmente das políticas financeiras engendradas pela política chinesa na África, que tem interesse estratégico no continente para compra de petróleo, commodities agrícolas e exploração de recursos minerais.

Mas há, sobretudo, o sentimento de que nos últimos sete anos, justamente os primeiros do novo século, a África vem superando o drama histórico das guerras intestinas e internacionais. ${ }^{5} \mathrm{O}$ número de países africanos com conflitos armados internos caiu de 13 para 5, nos últimos seis anos, apesar da dramaticidade do caso do Darfur. ${ }^{6}$ Os conflitos foram a mais importante causa imediata da pobreza no continente. A redução dramática dos mesmos faz pensar que os recursos, quase da ordem de US\$ 300 bilhōes queimados nos conflitos entre 1990 e 2005, podem agora ser dirigidos às políticas de redução da pobreza e da miséria. ${ }^{7}$

Há, ao mesmo tempo, uma onda democratizante dos regimes políticos em várias partes da África. Mesmo os critérios duvidosos da construção de variáveis para a taxonomia de democracia no mundo, propostos pela Freedom House, demonstram esse avanço inconteste. Um processo tardio, mas relevante, de consolidação de instituiçôes e governos na África com bases menos autocráticas e com algum apelo às noções da democracia é fato relevante para a elevação da confiança internacional. ${ }^{8}$

No Brasil, a reflexão acerca dos desafios africanos é modesta e tardia. A interpretação dominante acerca do futuro do continente é plasmada por olhares enviesados que se repetem com regularidade gritante. Meios de comunicação insistem em apresentar uma África indolente e ditatorial, onde o Brasil quase

5 Um bom estudo acerca das origins e dos desdobramentos desses conflitos está na obra de Taisier M. Ali \& Robert O. Mathews, Civil Wars in Africa. Roots and Resolutions. London: Ithaca, 1999.

6 Os conflitos na África foram chaga da história recente com impacto econômico incontestável, como demonstra o Relatório da ONG Oxfam, Iansã e Saferwood, que acaba de ser publicado: US\$ 284 bilhôes foi o custo para o desenvolvimento do continente causado pelos conflitos armados entre 1990 e 2005 . O curioso é que essa soma corresponde aproximadamente ao valor de toda a ajuda financeira internacional recebida pela África no mesmo período.

7 PNUD. Relatório do Desenvolvimento Humano, 2005 e 2006.

8 É evidente que, como um processo histórico recente, há idas e vindas na construção democrática dos Estados africanos contemporâneos. O caso recente do Quênia, considerada até pouco tempo um exemplo satisfatório de democratização gradual, demonstra que há reveses, mas há também negociação e sistema de pesos e contrapesos que tornam os encaminhamentos políticos não tão trágicos quanto aqueles pintados pelas visões da catástrofe africana. 
nada tem a fazer. ${ }^{9}$ Empresários e empresas nacionais, mesmo acumulando ganhos comerciais no momento, ainda duvidam das possibilidades do agir em terreno africano de forma mais duradoura, a impulsionar a logística que a África requer e que o Brasil pode bem aproveitar. ${ }^{10}$ As escolas continuam afônicas de histórias da África. ${ }^{11}$ As tragédias e genocídios ganham a cor espetacular das telas televisivas enquanto as experiências de estabilização e crescimento econômico assim como as iniciativas políticas de redução da pobreza e das doenças endêmicas na África são silenciadas.

Quando aparece a África no Brasil, chega enviesada e embalada por caleidoscópio de discursos intermediários que apenas envergam a vara para a percepção da África envolta nas questôes de discriminação racial e dos preconceitos domésticos brasileiros. O prisma que vincula a redução da reflexão da África contemporânea à dimensão da afro-brasilidade é interessante pois permite comunicar as Áfricas que existem dentro do Brasil com a diáspora e os africanos do outro lado do Atlântico Sul, porém é ângulo incompleto ao esforço de entendimento dos grandes desafios da inserção africana na ordem internacional do século XXI.

O insuficiente acompanhamento dos debates africanos contemporâneos no Brasil conjuga-se à ausência de significativos centros estratégicos voltados para o acompanhamento da nova corrida para a África. Daí a preocupação legítima de setores responsáveis no governo e na sociedade: há ainda um reumatismo crônico como força impeditiva do avançar o país na velocidade dos demais corredores na direção do continente africano. Sem conhecimento estratégico não há tática que permita avançar de forma duradoura e consistente um programa de ação do Brasil na África nas próximas décadas.

9 A sétima visita do presidente da República da Brasil, Inácio Lula da Silva, ao continente africano nos dias 15 e 19 de outubro de 2007, é momento recente e especial para ver o quanto, na grande imprensa, seguem os olhares enviesados e as atitudes de desconfiança acerca do que o Brasil pode realizar com a África. O desconhecimento médio de entrevistador e entrevistado é marca do que se viu nos jornais. Expressam a carência de reflexão sofisticada no Brasil acerca do que está ocorrendo naquele continente. Ver, por exemplo, o editorial "Diplomacia e Ditatura", Folha de São Paulo, 17 de outubro de 2007, bem como a entrevista, ao Correio Braziliense, do "Brazilianist" Thomas Skidmore: "Lula é um pernambucano que goza das viagens pelo mundo, e seu tour internacional o faz ter mais visibilidade que seus antecessores... A viagem à Africa é muito mais um show... O cara quer ir a todos os lugares. Algumas vezes parece que ele (Lula) deseja fugir de Brasília e dos problemas políticos., Correio Braziliense, Skidmore critica tour presidencial, 17 de outubro de 2007, p. 24.

10 Isso ocorre mesmo no contexto de forte expansão da presença comercial do Brasil na África e da África no Brasil, como demonstram os dados do Ministério do Desenvolvimento, Indústria e Comércio Exterior. Apesar do crescimento, de 2002 para 2006, do fluxo comercial entre o Brasil e a África de US\$ 5 para US\$ 15,5 bilhōes, não se percebe uma estratégia empresarial de longo prazo a cuidar para que a presença do comercial migre para os investimentos em logísitica e sustentabilidade dessa área relevante para a diversificação de parcerias comerciais e políticas do Brasil. Tal crescimento se dá mais, para alguns analistas com meu colega Wolfgang Döpcke, pelo crescimento inercial da economia global e seus impactos no Brasil e na África. Mas há que registrar-se, por exemplo, a nova linha de crédito anunciado pelo BNDES para Angola, em torno de US\$ 1 bilhão, na visita do presidente Lula àquele país em 18 de outubro último, como um movimento altamente favorável a uma presença mais induzida pelo Brasil, pelo próprio Estado nacional.

11 A produção nacional de livros a respeito da África é escassa, em geral sem pesquisa in loco, além de reproduzirem, em grande medida, visōes românticas ou voltadas para o estudo do outro lado do Atlântico Sul apenas pela via politizada do discurso da afro-brasilidade. 
Em síntese, a percepção da inteligência africana acerca do seu próprio futuro é matéria oculta, água turva, no seio do conhecimento brasileiro hegemônico disseminado nas universidades, empresas, agências de governo e meios de comunicação, senão mesmo nas veias da ação pragmática do Brasil para a África. A baixa apreciação da África por parte da mídia e de agentes sociais e econômicos brasileiros, no entanto, não corresponde à ação e à apreciação do Executivo, mais elevada. Essa é uma área correta do governo Lula, que evoluiu nessa matéria em relação às dificuldades do governo Cardoso. ${ }^{12}$

\section{Cinco décadas de independência africana e desafios dos Estados novos: renascença e nova partilha internacional}

A África caminha mais célere e autoconfiante nos dias que nos cercam que o que se colhe nas manchetes dos jornais. Caminhará o continente, ao longo dos próximos anos, nas trilhas do cinqüentenário da sua liberdade política. São Estados novos, ainda infantes, quando comparados com as velhas democracias européias ou os Estados latino-americanos de 200 anos. Em todo caso, o ano de 2007 trouxer valor simbólico: é o meio século da independência da Costa do Ouro (Gana de hoje), a primeira da África Negra, liderada por N’Krumah em 1957. O ano de 2008 inaugura uma sequiência de atos e reflexōes acerca do lugar da África no mundo, fora e dentro do continente. As mensagens não de algum otimismo cauteloso.

Iniciativas políticas e culturais convocam a comunidade internacional para o compartilhar do renascimento africano, embora não mais aquele das nascentes independências em fins dos anos 1950 e início da década de 1960, povoada por rancores anti-coloniais, romantismos revolucionários e jargóes de libertadores ingênuos. Nem é o renascimento pós-apartheid apenas, alardeado pelo governo de Pretória, embora seu próprio renascimento nacional esteja na moldura mais ampla do que aqui chamo de renascimento africano. Também não se está falando do renascimento político dos anos 1960 e 1970, que já ficou para trás, nos debates recorrentes das elites africanas entre as idéias de Senghor e Cabral. ${ }^{13}$

12 Ver alguns livros meus e de colegas brasileiros a respeito da política africana do Brasil, no passado e no presente: José Flávio Sombra Saraiva, O lugar da Africa: a dimensão atlântica da politica exterior do Brasil. Brasília: Editora da UnB, 1996; José Flávio Sombra Saraiva \& Amado Luiz Cervo (orgs.), O crescimento das relaçôes internacionais do Brasil. Brasília: Instituto Brasileiro de Relações Internacionais, 2005; José Flávio Sombra Saraiva, África e o Brasil: o Fórum de Fortaleza e o relançamento da política africana do Brasil no governo Lula. In: Pedro Mota Coelho \& José Flávio Sombra Saraiva (orgs.), Fórum Brasil-Africa: Política, Cooperação e Comércio. Brasília: Instituto Brasileiro de Relações Internacionais (IBRI), 2004, p. 295-307; José Flávio Sombra Saraiva, A política exterior do governo Lula: o desafio africano, Revista Brasileira de Politica Internacional, 45 (2), 2002, p. 5-25.

13 Há 20 anos estudei aquele outro intento de renascimento africano, naquela época marcado pelo grande debate ideológico entre uma África que renascia entre acomodações aos padrões neocoloniais, sob o manto do conceito de negritude de Leopold Senghor, e o grito revolucionário, da luta armada como teoria de libertação de Amílcar Cabral. Ver José Flávio Sombra Saraiva, Formaçāo da África Contemporânea, São Paulo: Editora da Unicamp/ Atual, 1987, capítulo "Renascimento cultural na África contemporânea", p. 6-16. Ver também os debates clássicos propostos por Paulin J. Hountondji, Sur la "philosophie africaine". Paris: Maspero, 1980; Ola Balogun, Honorat Aguessy, Pathé Diagne, Alpha Sow, Introdução à cultura africana. Lisboa: Edições 70, 1977. 
A África não quer remoer o passado à cata de culpados. Quer caminhar para frente. O renascimento do início do século XXI é mais altruísta, evidencia uma outra forma de renascer, mais eficaz que a anterior, mais pragmática, a fazer referência a outras formas obliteradas de africanidade pelos discursos políticos engendrados pelas ideologias da Guerra Fria e do nacionalismo teórico e político da primeira geração das independências. Há um outro renascimento, novos consensos, com outras referências culturais, políticas e sociais, com resultantes a serem alcançadas no mundo que vem aí.

Ícones da profundidade de campo histórico da África (para utilizar as imagens de Abdel Malek ${ }^{14}$ e C. A. Diop) vêm sendo trazidos para a discussão do futuro do continente. É este, a título de exemplo, o caso de Tombuctu, cidade antiqüíssima nas margens do Níger, que se revitaliza nos dias de hoje não como memória do classicismo africano, mas como lugar do presente da cultura africana e imaginação de um devir político soberano e altruísta do continente. ${ }^{15}$ A outra é o renascimento que bebe da historiografia de Heinrich Barth, revista na obra recente de Mamadou Diawarq, Paulo Fernando de Moraes Farias e Gerd Spittler. ${ }^{16}$ Ou mesmo da recuperação das obras de Ibn Haldun ou, alguns séculos depois, de Edward Blyden.

Animados por um conjunto de atividades acadêmicas, políticas e culturais, os africanos relembram, em várias partes do continente, o soleil des indépendances, mas em especial passam em revista os descaminhos de várias experiências de importação de modelos, como as reformas estruturais conduzidas pela "genialidade liberal", os planos de reestruturação conduzidos pelos economistas do Ocidente ou mesmo a cópia em papel carbono do socialismo real e do modelo do partido único de matriz stalinista. Passarão em revista os 53 Estados nacionais da África, de forma crítica, nos próximos anos, a evolução mais recente das cinco décadas de autonomia jurídica, ainda que na política apenas de forma relativa, pois necessitam preparar suas casas para uma inserção mais altaneira na ordem internacional do século XXI. ${ }^{17}$

14 Anouar Abel-Malek, Sociologia del imperialismo. Ciudad de México: Universidad Nacional Autônoma de México, 1977;

15 Ver o texto de Paulo Fernando de Morais Farias (Centre of West African Studies, University of Birmingham, Inglaterra) preparado para o seminário preparatório dos temas africanos para a II CNPEPI, em 2 e 3 de março de 2007, intitulado "Tombuctu, a África do Sul e o idiona de renascença africana”. É Paulo Farias que lembra que "por definição, o atual idioma da Renascença Africana se refere tanto ao presente quanto ao passado, dentro e fora das fronteiras da África do Sul, o país onde tem sido proclamado". É também de Paulo Farias outras duas idéias lapidares para o debate em curso: primeiro, "o papel dos cronistas de Tombuctu na invenção do esquema não tem sido reconhecido, porque a função que lhes é imposta pelos discursos posteriores é outra. As crônicas passaram a ser vistas sobretudo como testemunhas de uma grandeza saheliana perdida, que simboliza o futuro a ganhar. As tensões sociais e audácias intelectuais da Tombuctu do século XVII são substituídas pela imagem de um classicismo africano estereotipado"; segundo, "todo discurso de renascença corre o risco de mitificar o passado. Mas esse risco não inevitável, e subtrair-se a ele é também uma maneira de preservar a capacidade crítica em relação ao presente e aos caminhos para o futuro."

16 Mamadou Diawara, Paulo Fernando de Moraes Farias et Gerd Spittler, Heinrich Barth et l'Afrique. Köln: Rüdiger Köppe Verlag, 2006.

17 Modelar o balance dos 30 anos da independência da África realizado por Douglas Rimmer, em 1991, com prefácio da Princesa Diana, em nome da Royal African Society britânico. Ver Douglas Rimmer (ed.), África 30 
O renascimento africano coloca aquele continente na berlinda da cena internacional contemporânea. Afinal, está-se a falar de quase um quarto da superfície do planeta (22,5\% das terras do globo), com 30 milhôes de quilômetros quadrados, com $10 \%$ da população do mundo, mas que deverá dobrar até $2050 .{ }^{18}$

Senhora de recursos minerais globais, a África é fonte de cobiça por cerca de $66 \%$ do diamante do mundo, $58 \%$ do ouro, $45 \%$ do cobalto, $17 \%$ do manganês, $15 \%$ da bauxita, $15 \%$ do zinco e $10 \%$ a $15 \%$ do petróleo. São aproximadamente 30 os recursos minerais do mundo que a África guarda em seu subsolo. Mas só participa de $2 \%$ do comércio mundial e possui apenas $1 \%$ da produção industrial global. Há, portanto, um enorme desafio de elevação desses itens.

Em outras palavras: cultura, poder e economia começam a caminhar juntas e de forma mais organizada para os africanos que estão na África do século XXI, mais do que para aqueles outros que, em nome de uma África onde jamais pisaram ou estudaram, querem guardar, fora da África, nos seus países, uma África imaginária ou politizada por razões de demandas internas e sociais de ascenso social. A África não se interessa tanto por isso. Os africanos não querem que seu continente do século XXI seja lido como fonte da imaginação política dos outros, mesmo de seus descendentes nas Américas, apenas como um lugar sagrado do passado, de dívidas históricas espalhadas por todo o mundo e do diálogo global dos afro-descendentes informado da noção da diáspora. Embora tais temas sejam relevantes, não são as prioridades do momento vivido pelas sociedades africanas no novo século.

Em meados da primeira década do novo século, as amarras da velha colonização cedem lugar às iniciativas das lideranças africanas. Há uma percepção que se generaliza de crescente responsabilidade das elites domésticas com o encaminhar do futuro. $\mathrm{O}$ discurso da vitimização da história continental é substituído por raciocínios mais pragmáticos. A idéia do aproveitamento de oportunidades inéditas abertas pela quadra histórica da primeira década do século XXI permeia o novo discurso interno da inteligência africana.

Por outro lado, seria inocência intelectual e irresponsabilidade política imaginar que o destino africano pertence, de forma exclusiva, à esfera da autonomia decisória de seus líderes nacionais. Há um novo mapa africano, não aquele desenhado pelos colonizadores de antes, mas não menos inquietante ante a força incontestável de seus desenhistas. Desfilam em Abuja, Adis Abeba. Lagos, Luanda, Cartum, Pretória, Cairo ou Maputo autoridades chinesas, norte-americanas, brasileiras, agentes de empresas multinacionais e organizações não-governamentais.

Atores internacionais de toda ordem, cada vez menos as organizaçóes nãogovernamentais humanitárias dos países ricos e cada vez mais atores econômicos

Years On. London: James Currey, 1991. Indicava já aquele documento do início dos anos 1990 que a África necessitaria voltar-se para si mesmo, para dentro, para sair de suas crises.

18 Vale aqui lembrar que os mais de cerca de 600 milhões de africanos serão, na segunda metade do século XXI, em torno de um bilhão de 200 milhões de pessoas. Tomando-se em conta a grande população de velhos na China e o modesto crescimento vegetativo da Índia, a África, ao lado dos outros dois países, serão as áreas mais populosas do mundo no final do século XXI. 
e estratégicos globais, querem dividir, com os africanos, balanços e projeções que já se preparam, no seio dos institutos africanos e mundiais, acerca da última fronteira territorial da internacionalização econômica do capitalismo. ${ }^{19}$

Há, portanto, uma relação biunívoca, mas também dialética, entre o interno e o externo. Se por um lado é desejável que a África supere o drama histórico do colonialismo e do atraso (lugar do discurso do renascimento africano das primeiras décadas das independências), há, por outro, a preocupação de que novos arranjos entre as elites locais e internacionais não tragam a autonomia decisória nem o desenvolvimento sustentável ao continente (lócus do discurso do novo renascimento africano). ${ }^{20}$ É do nigeriano Claude Ake, em seu ensaio Democracy and Development in África a seguinte preocupação:

The problem in not so much that development has failed, as that it was never really on the agenda in the first place. ${ }^{21}$

Há o temor, por trás da internacionalização crescente do continente africano, de que o "caráter exógeno" do Estado africano pós-colonial, como gosta de definir Carlos Lopes, ${ }^{22}$ o sociólogo onusiano nascido na África de língua portuguesa - se perpetue com novas máscaras. A preocupação legítima do ilustre africano vai ao ponto focal: como diminuir a distância mental e real, produzida pelos próprios governantes de grande parte dos Estados africanos modernos, entre os abismos sociais e políticos que separam ricos de pobres, elite de povo, na África das próximas décadas do século XXI?

Nota-se desde já até mesmo reaçôes de agentes econômicos, políticos e intelectuais africanos contra a lógica de sua reinternacionalização, sob o manto de uma nova partilha africana, um novo Congresso de Berlim em curso, mantendo as formas de dominação e estratificação social e concentração de poder dos Estados pós-coloniais na África. Esse sobressalto veio à tona recentemente por meio de várias vozes importantes da inteligência africana como o filósofo senegalês Yoro Fall. Também chamou a atenção Ali Mazrui, um dos mais prestigiados politólogos africanos contemporâneos, que a África está à busca de sua própria Doutrina Monroe, da África para os africanos. ${ }^{23}$

19 Ver os relatórios de 2006 e 2007 do BIRD e do FMI, nos capítulos referentes às oportunidades de crescimento mais sustentável das economias africanas para os próximos anos.

20 Esse tema foi particularmente tratado recentemente, pela obra mais difundida acerca dos 50 anos da independência africana pelo britânico Martin Meredith, The State of África: a History of Fifty Years of Independence. London: Free Press, 2006. É dele a frase:

21 Apud Martin Meredith, op. cit., p. 688.

22 Conversas com o colega quando esteve no Brasil como representante do PNUD e do sistema onusiano em Brasília.

23 Ali Mazrui alertou para esse problema na abertura da Conferência Internacional "Democracy and Peace: Dialogue between Africa and Latin América”, Jos Univerity, Ibadan University, em Abuja, 2000, conferência a qual tive a honra de participar como membro da delegação latino-americana. 
Para Mazrui, até a redução de conflitos armados internos ou que envolvem relações internacionais na África não podem ser resolvidos por soluçōes puramente exógenas, necessitam soluçôes domésticas e dirigidas por novo consenso entre povo e elites locais. Provoca-nos abertamente o velho mestre da arte política africana:

The pursuit of Africa's peace by African themselves, however, is not just an extension of international peecekeeping, but rather is a process of Pax Africana. ${ }^{24}$

\section{A África entre teleologia, deontologia e escatologia. A saída para um lugar alvissareiro no seio da ordem internacional do século XXI}

Á África é uma das regiōes do mundo que, historicamente, mais esteve próxima às tentaçōes de interpretaçóes apaixonadas acerca das relaçóes entre passado e futuro. Escrutinada sob as óticas da teleologia, da deontologia e da escatologia, às vezes simultaneamente, a África segue sendo um lugar para o teste da razão crítica contra o monumento de preconceitos que foram erigidos pela fraca ciência e pela opinião desinformada.

O nível teleológico de análise, ao animar a avaliação das ações por meio de suas conseqüências, condenou o agir da África a um eterno desterro e o passado africano à mera preparação da obra civilizatória inconclusa do Ocidente. A conseqüência dessa lógica no seio da historiografia e da sociologia nacionalista africana foi óbvia: todos os males de hoje adviriam, então, de um pecado original, o do colonialismo e suas conseqüências. É esse o raciocínio que amarra a reconstrução do passado a um presente infértil, plasmado por "afro-pessimismo" que vigorou até pouco e que ainda persegue mentes cultas e especializadas nos assuntos africanos em vários centros de estudos estratégicos no mundo, mesmo no Brasil de poucos estudos.

O nível deontológico, ao julgar ações conforme regras formais em função da distinção entre o bem e o mal, encapsulou a África no plano do mal, reduzindo-a à incapacidade histórica das elites e do povo de constituir lá sociedades burguesas civilizadas e integradas aos fluxos da economia política global. Há uma velha marcha hegeliana, amplamente cantada pela literatura especializada, que empurrou a África para o campo dos povos sem história, de um "passado inenarrável", o qual Farias recentemente reviu. ${ }^{25}$ A maldição da África, para os céticos, seria a impossibilidade de narrar o passado e, portanto, construir o futuro, reduzindo-a à eterna infância. Até o Dr. Watson, prêmio Nobel de medicina do início dos anos 60 com o tema do DNA, em pleno

24 Ali Mazrui, "Foreword". Em: Ricardo R. Lauremont (ed), The causes of war and the consequences of peacekeeping in Africa. Portsmounth: Heinemann, 2002, p. xi.

25 Paulo F. de M. Farias, “Tombuctu..., op. cit. 
início século XXI, na terceira semana do mês de outubro de 2007, acaba de pronunciar, para depois desdizer, que "Africans are not so intelligent such as Westerns". ${ }^{26}$

A sucessão de ilogicidades, de ausência de razão crítica, herdeiras elas do discurso hegeliano, empurrou bastante a ciência e a opinião pública, nas últimas décadas, ao discurso da inviabilidade da África. É o plano escatológico, plasmado por imagens, autores e meios da corrente afro-pessimista dos anos 1990.

Teses vêm sendo utilizadas, nessas bases esquemáticas, e em várias partes do mundo, na lógica da "marginalidade" africana e de sua desimportância para o quadro geral da ação externa dos Estados e das relações internacionais do século XXI.

Ledo engano. A África jamais foi marginal, no passado nem no presente. O conceito da marginalidade africana é insustentável, teórica e empiricamente. Não são apenas os africanos que se insurgem contra essa escatologia, mas a massa de literatura atualizada acerca dos desafios africanos no xadrez da política internacional. É Jean-François Bayart, como também depois Ian Taylor e Paul Williams, no importantíssimo livro intitulado Africa in Iternational Politics: Extermal Involvment on the Continent, ${ }^{27}$ quem abre a crítica à escatologia antiafricana nos temas da política internacional para o início do século XXI:

More than ever, the discourse of on Africa's marginality is a non sense discourse. ${ }^{28}$

O mundo está atento à África como sempre estiveram as grandes potências e as ex-metrópoles. O peso da África na Guerra Fria não se circunscreveu a ser margem do sistema internacional. São os dois autores anteriores que nos lembram:

Africa has never existed apart from world politics but has been unavoidably entangled in the ebb and flow of events and changing configurations of power. (...) In practice, Africa cannot enjoy 'a relationship" with world politics because Africa is in no sense extraneous to the world. The continent has in fact been dialectically linked, both shaping and being shaped by international processes and structures. ${ }^{29}$

O mundo está, portanto, acompanhando com a máxima atenção a reinserção africana na política internacional. Records e outlooks vêm sendo lançados com profecias otimistas acerca das escolhas políticas e do novo perfil de desenvolvimento

26 Conforme amplamente divulgado pelos meios de comunicação nos dias 18 e 19 de outubro do corrente ano pelas televisōes e jornais, depois de sua desastrosa entrevista para a BBC.

27 Ian Taylor \& Paul Wiilliams (eds), Africa in International Politics: External Involvment on the Continent. London: Routledge, 2004.

28 Idem, página 1.

29 Ian Tayor \& Paul Williams, op. cit., p. 1. 
social que a África requer. Vê-se essa tendência desde as avaliações produzidos pelos Royal African Society do Reino Unido. ${ }^{30}$

O mais recente desses documentos é o interessantíssimo trabalho, com fins estratégicos, organizado pelos colegas professores Samantha Power (da Universidade de Harvard) e Anthony Lake (da Georgetown University), em fins de 2006, ladeando o ex-secretário de Estado assistente para África dos Estados Unidos, Chester Crocker. Lançado em 2007 pelo afamado Council of Foreign Relations, dos Estados Unidos, nota-se perfeitamente a retomada da prioridade africana na política externa norte-americana. ${ }^{31}$

More than Humanitarianism, o título da estratégia norte-americana fala por si, ao lançar as bases conceituais para a ação dos norte-americanos para a África nas próximas décadas. Pragmatismo mais do que humanitarismo, disputa por recursos minerais, ampliação da diversificação no campo da energia, cooperação com os governos democráticos e ocupação de espaços na luta contra o terrorismo são as linhas gerais de trabalho para os próximos 20 anos dos Estadus Unidos na África. Querem disputar a partilha com as ex-metrópoles, particularmente Inglaterra e França, mas sobretudo querem enfrentar a potência do dragão oriental.

Nenhuma polaridade estatal foi tão hábil na elaboração estratégica para a África quanto a China do primeiro ministro Li Peng, já nos fins da década de 1980 e início dos anos 90. O marco é o dia 4 de junho de 1989, o drama da Praça da Paz Celestial e o isolamento imposto pelo Ocidente ao regime político de Pequim. Começava a conexão África-China, que tem todas as condições de ser a mais duradoura sobre todos os demais intentos de qualquer unidade estatal, mesmo dos Estados Unidos, de estabelecer bases de cooperação ativa como o renascimento africano.

A estratégia chinesa é explícita: a) exportação para a África do modelo chinês de tratamento dos temas da agenda internacional, apresentando-se como uma representante natural dos países em desenvolvimento; b) exportação de bens industriais e armas e importação de produtos primários; c) exploração de todas as fontes possíveis e necessárias de recursos minerais, estratégicos e de energia que garanta a sustentabilidade do crescimento econômico chinês. $\mathrm{O}$ método tático para a consecução dos objetivos é múltiplo: varia dos investimentos, empréstimos e doações à cooperação técnica e tecnológica, além de exercício de cooptação política das elites africanas. $\mathrm{O}$ ambiente político da cooperação abraça o econômico como parte da grande engenharia estratégica que foi elaborada, empiricamente,

30 Seguindo a tradição dos ingleses de revisão, a cada duas ou três décadas, de avaliação das grande tendências em curso na África. Destaca-se, por exemplo, o balanço de 1991, já um pouco ultrapassado, mas bastante interessante pelas visōes mescladas, entre otimismo e pessimismo, acerca do futuro da África quanto aquele organizado pelo Royal African Society sob os auspícios do meu mestre em Birmingham, Inglaterra, Douglas Rimmer, op. cit. É de Douglas Rimmer a seguinte assertiva, produzida em 1991, e de grande atualidade para o renascimento africano: "Responsible governments, competent governments, and governments limited in their agenda to what they can usefully achieve are the second requiremente of a better future in África", p. 13.

31 CFR, More than Humanitarianism: A Strategic US Approach towards Africa. Washington: Council on Foreign Relaitons, 2007. 
na base do isolamento político do regime chinês depois do evento de 4 de junho de 1989 e a solidariedade conferida por grande maioria dos governos na África, depois de serem cortejados com recursos chineses.

Foi o primeiro-ministro Li Peng quem coordenou toda a operação de aproximação com uma das poucas regióes do mundo que não se movera contra o massacre de jovens na China: os governos africanos. Para exemplificar, a China oferecia, em 1988, apenas US\$ 60 milhões de ajuda direta a 30 países da África, mas em 1990, depois do apoio dos governos africanos ao regime de Pequim, receberam tais países a soma de US\$374, para chegar aos volumes bilionários dos chineses hoje na África. Embora predominantemente econômica, a presença chinesa na África origina-se da política e seguirá tendo uma forte conotação política e estratégica. Vejam as palavras de Li Peng, em 12 de março de 1990, na chegada a Pequim de imensa delegação de chefes de Estados africanos:

A nova ordem política internacional significa que todos os países são iguais, e devem respeitar os outros com relação a suas diferenças no sistema político e na ideologia. Eles (os países capitalistas do centro e as democracias ocidentais) não podem interferir os assuntos domésticos dos países em desenvolvimento, especialmente avançar poder político em nome de "direitos humanos, liberdade e democracia". ${ }^{32}$

Livros lançados recentemente dão conta da preocupação da grande parceira comercial e política da África na Europa, que é a França, além de ser a maior investidora individual no conjunto da economia africana. ${ }^{33}$ Tanto há preocupaçôes na área comercial quanto na área da cooperação direta da China com regimes políticos na África que desrespeitam o capítulo dos direitos humanos. Daniela Kroslak estudou essa matéria de forma mais detalhada, com ênfase ao tema do envolvimento militar da França naquele continente. ${ }^{34}$

O fato objetivo é que, desde 1990, renovando-se em 2000 com a criação do Fórum de Cooperação África-China, no qual 80 ministros de Estado africanos foram levados de Pequim à área industrial de Guandong em avião para verem o colosso do crescimento industrial chinês, passando pela segunda edição, em novembro de 2006, do Fórum de Cooperação, além da terceira visita do presidente Hu Jintao à África em fevereiro de 2007, a China desembarcou na África de forma estrutural. É difícil andar em qualquer rua comercial de qualquer país africano que não esteja inundada por produtos chineses. Não há capital na África sem uma obra pública imponente feita com recursos chineses. Não há infra-estrutura importante de aeroportos e estradas que não tenha uma mão chinesa.

32 Apud Ian Taylor, "The all-weather friend? Sino-African interaction in the twenty-first century" in Ian Taylor \& Paul Williams, op. cit., p. 87.

33 Adama Gaye, Chine-Afrique: le dragon et llautruche. Paris: L'Harmattan, 2006; Jean-François Susbielle, Chine-USA: la guerre programe. Paris: Ed. Générale First, 2006, capítulso "La conqête pacifique de l'Afrique", pp. 231-232; Armand Tenesso, La nouvelle destine de l'Afrique. Paris: L'Harmattan, 2006.

34 Daniela Kroslak, France’s policy towards África In: Ian Taylor and Paul Williams, op. cit., p. 61-82. 
Como à época do desenvolvimentismo, fase na qual o Brasil praticava uma diplomacia cooperativa e não-confrontacionista, a China dos últimos anos buscou a África sem truculência, violência ou presunção de superioridade, traços da diplomacia européia e norte-americana. O Brasil mesmo está tentando voltar, na nova quadra histórica do início do século XXI, como demonstram as prioridades da diplomacia de Amorim. ${ }^{35}$

Em síntese, há uma África em crescente internacionalização e nada marginal. Ela está no centro de uma concorrência fortíssima de interesses e interessados de todas partes do globo. Se os investimentos externos diretos crescem de forma consistente, oriundos tanto das grandes empresas financeiras e produtivas, é também verdade que esses investimentos estão dirigidos por certa lógica de ocupação territorial e estratégica da África por grandes potências, instituiçōes multilaterais e influentes grupos econômicos globais ancorados em bases estatais. Nesse aspecto, o futuro estratégico do continente africano está sendo traçado de fora para dentro.

\section{O experimento de modernização, democratização e inserção internacional na África de língua oficial portuguesa: o caso de Moçambique}

Os países de língua portuguesa na África são casos interessantes para se notar o quanto o argumento central deste artigo se comprova no campo experimental. Angola cresce seu PIB anual em torno de quase 20\%, um dos maiores do mundo. Cabo Verde assiste a sua internacionalização crescente, mesmo nas condições difíceis do arquipélago. São Tomé e Príncipe normalizam sua vida política e abre as portas para os investimentos na sua plataforma petrolífera. A Guiné Bissau, apesar dos problemas que passou na última década da história, assiste sopro de esperança de normalização política.

Moçambique, mais até que os acima citados, é caso modelar de inserção internacional altaneira na ordem internacional do início do século XXI. O país foi vistoriado de forma alvissareira nos relatórios de agências internacionais, como o Fundo Monetário Internacional e o Banco Mundial em fins de 2006. ${ }^{36}$ Apontam tais documentos potencialidades econômicas únicas na quadra histórica atual do continente africano. Rejubilam-se investidores externos e nacionais pelo bom desempenho político e pelo equilíbrio macroeconômico daquela nação africana. As razões para o otimismo derivam de fatos como a democratização em ritmo mais forte que muitos dos Estados africanos, reformas econômicas liberalizantes que criaram confiança nos mercados, crescimento do PIB na ordem de 7\% nos

35 Ver o início de avaliação desse movimento do Brasil em artigo relativo à conferência que preparei para evento anterior organizado pelo Ministério das Relações Exteriores: José Flávio Sombra Saraiva, Moçambique em retrato 3x4: Uma pequena brecha para a política africana do Brasil. Em: Seminário Preparatório "África”, para a II Conferência Nacional de Política Externa e Política Internacional, 2 de março de 2007.

36 IMF \& BIRD, Africa Foreign Investment Survey 2005. 2006. 
últimos anos, inflação domada, diminuição da vulnerabilidade externa, reservas internacionais consideradas satisfatórias para uma economia modesta e acesso a financiamentos internacionais.

Mesmo quando não há comércio bilateral expressivo, Moçambique incluise crescentemente em périplos recentes de vários chefes de Estado, interessados em projeção internacional na África. A visita a Maputo, entre os dias 7 e 8 de fevereiro de 2007, por cerca de 24 horas, do presidente chinês Hu Jintao, é fato político com impacto na corrida já não mais tão secreta em favor de uma nova partilha africana. ${ }^{37}$

Mas o que há com Moçambique, pobre economia africana, tão desigual na distribuição da renda e tão modesta estrategicamente, que a faz atrair tanta atenção? Que buscam os grandes naquele Estado de língua portuguesa, incrustado na porção índica da África, de costas para o Atlântico, diferentemente de todos os demais países que compóem, naquele continente e nas Américas, o legado complexo da expansão ultramar portuguesa?

Moçambique não é apenas um lugar da lusofonia do outro lado da África ou um dos Estados de recente independência formal, em processo tardio de consolidação de instituiçôes e da democracia. Moçambique tampouco é apenas um país dependente economicamente e desdenhado pelas elites de Pretória, embora saibamos que muitos sul-africanos ainda consideram o vizinho apenas sua décima província. ${ }^{38}$

Os vetores de poder agora são outros, bastante mais poderosos e pragmáticos. Envolta na sedução crescente da China, e também da Índia, ávidas por recursos minerais, estratégicos, energéticos, mas também de portos, de produtos agrícolas e mesmo de ocupação territorial via deslocamento de populações e até mesmo pelo turismo, Moçambique está na berlinda.

Maputo é uma das portas, com entrada facilitada na geografia moçambicana, ao "corredor turístico", como falou o presidente da China em sua recente visita ao país. Moçambique se insere, portanto, na ocupação de uma das últimas fronteiras do capitalismo mundial: o continente africano. Essa partilha não requererá um novo Congresso de Berlim. O mundo pós-Guerra Fria é mais sutil, mas não menos pragmático. Os chineses não vieram apenas para o controle de recursos

37 Os jornais e revistas moçambicanas e internacionais desses dias festejam ou vêem com desconfiança a estratégica visita realizada, no contexto do tour do presidente chinês por vários países da região. Ver: Beijing Time 5/2/07; Beijing/AFP/Turkishpress.com 30/1/07; Le Monde - Economie 15/12/06; Le Monde/AFP/Reuters 30/1/07; Notícias 8/2/07; Notícias Lusófonas 5/2/07; The Guardian 31/1/07; Xinhua News Agency 9/2/07.

$38 \mathrm{Ver}$, nesse caso, o impressionante relatório preparado pelo South African Institute or International Affairs (SAIIA), publicado em 2002, intitulado Cada continente precisa de seu Estados Unidos da América, voltado ao balanço e endosso da presença semi-hegemônica que a África do Sul procura impor a Moçambique. Um trecho do documento fala por si: "Over the last 10 years, Mozambique, sometimes touted as South Africa's tenth province, has emerged as one of the most significant South Africa investment destinations on the African continent. South Africa is a leading investor in that country representing $49 \%$ of total foreign direct investment (FDI) from 1997-2002. South African companies have capitalized on Mozambique's geographical proximity to expand their reach into the continent" (p. 1) Ver GROBBELAAR, N. Every Continent Needs an America. Pretoria: SAIIA, 2002. 
energéticos, minerais e estratégicos na África. Vieram ampliar poder de barganha no cenário internacional. ${ }^{39}$

Elites econômicas e políticas moçambicanas não iriam assistir, de binóculos, a novos arranjos da entente Angola-África do Sul sem ajustar os graus dos seus interesses na região. Foram à busca do seu lugar e da afirmação de seus interesses. Estão gradualmente pavimentando seu próprio caminho. E a Copa do Mundo de Futebol de 2010 na África do Sul provê à imaginação lacaniana das elites de Maputo a idéia de um renascimento moçambicano nos novos tempos da África.

O balanço da evolução democrática em Moçambique é satisfatório. Não variou em relação à grande maioria dos países africanos na sua dimensão pluriétnica, na preservação do Estado territorial herdado da colonização bem como na baixa densidade de participação da sociedade civil nas decisões e no acompanhamento das políticas encaminhadas pelo aparelho de Estado. De fracas a inconclusas ou deformadas, de todas as formas já foram metaforizadas as débeis democracias africanas. Mas o joio pode ser separado do trigo, como hoje reconhecem as próprias agências internacionais.

A tênue democracia moçambicana é diferente no que se refere à capacidade de chegar a uma estabilidade relativamente engenhosa. Soube adaptar a vida política nacional aos processos de internacionalização econômica que passaram a operar no continente na última década e no início do novo século sem perda de tempo. Moçambique buscou demonstrar ao mundo externo que é uma democracia moderna em formação e que combate os excessos gerados pela corrupção e pelo patrimonialismo. ${ }^{40}$

A favor das elites moçambicanas - mas naturalmente estimuladas pela indução do governo de Pretoria - está o fato de que lograram reconstruir o Estado, sem fragmentaçõos fratricidas, sem pressão das diferenças étnicas, sem separatismos regionais e banindo sublevaçôes. O espraiar de uma certa idéia de Estado vem facilitando contatos internacionais e inibindo desestabilizações internas, o que já é muito para o histórico da formação do Estado no continente africano. É esse Estado moçambicano que vem permitindo o crescimento econômico continuado, o incremento dos investimentos estrangeiros e das exportações, além de certa constância nos níveis de ajuda internacional. ${ }^{41}$ Ganhou o status de "democracia eleitoral" e de país "parcialmente livre" nas classificaçōes da Freedom House de 2005. ${ }^{42}$

39 Ver, por exemplo, os trabalhos de Scarlett Cornelissen, a respeito do avanço japonês na África, e a impressionante radiografia de Ian Taylor concernente ao desembarque do governo de Hu Jintao na África: Cornelissen, S. JapanAfrica relations: patterns and prospects. In: Taylor, Ian \& Williams, P. Africa in International Politics: External Involvment on the Continent. London: Routledge, 2004, pp. 116-135; Taylor, I. The 'all-weather friend'? SinoAfrican interaction in the twenty-first century. In Taylor, Ian \& Williams, Paul, op. cit. p. 83-101.

40 Esclarece-se, no entanto, que não há unanimidade entre os estudiosos da África contemporânea acerca dessa matéria. Para alguns deles, como Döcpke, o que diferencia a corrupção moçambicana da angolana é a proporção da economia. Haveria menos a distribuir em Moçambique que em Angola. (Entrevista com o especialista)

41 Olsen, C. A luta continua: a formação do Estado em Moçambique. Brasília: MRE, Instituto Rio Branco, 2006, p. 48. (Orientador: José Flávio Sombra Saraiva)

42 Ver www.freedomhouse.org. 
Essas avaliações, contudo, não inibem a articulação do Estado moçambicano com os novos agentes econômicos internacionais e com os investimentos diversos, de fontes múltiplas. O raciocínio que alimentou o processo decisório é claro: se a pobreza e a Aids demandam programas específicos de financiamento, eles foram criados de alguma maneira, com ou sem a cooperação internacional. Mas se os investimentos produtivos na economia em expansão podem ser feitos, devem ser feitos com os capitais de onde puderem vir. Visões pragmáticas dominaram essa dimensão do processo decisório do país.

Moçambique passou a ser apresentado, em alguns fóruns econômicos, como espécie de "tigre" africano, por lembrar o caso da Ásia nas décadas de 1980 e 1990. Em 1998 foi considerada a economia que mais crescia na África. O país ultrapassou, nos últimos anos, todas as metas estabelecidas pelas instituições financeiras internacionais. Chama a atenção, todavia, o padrão das relaçóes econômicas externas moçambicanas. Segue o modelo da relação colonial, de exportador de produtos primários e importador de bens com alto valor agregado. Esse é um ponto de preocupação para setores sociais e políticos do país, embora nem sempre de sua elite governante.

Sem margem de dúvida, a situação moçambicana segue a das economias mais dinâmicas da África. A diversificação de parceiros internacionais, na raiz da modernização econômica, faz de Moçambique caso no qual investidores do Sul e do Norte praticamente dividem, meio a meio, o espaço africano. Ap se avaliarem os mais importantes investidores externos em Moçambique, é também elucidativo o movimento global empreendido pelo país e pelos capitais produtivos e financeiros internacionais. Há uma preferência, a manter certa capacidade operativa do Estado, de joint-ventures de empresas moçambicanas públicas com sul-africanas e européias, além das chinesas que estão aportando a Maputo e que ainda não puderam ser mensuradas inteiramente pelos dados relativos aos tempos mais recentes.

Registre-se o fato de que Moçambique está também submetido ao fenômeno da "reverse dependence", no qual as instituiçōes internacionais necessitam mostrar resultados em um país africano para mostrar ao mundo. Com pouco para barganhar, Moçambique tem o trunfo de que tais agências, investidores e doadores necessitam de certa eficiência e eficácia nas políticas por eles sugeridas. Resultado diverso tornaria difícil a sobrevivência desses doadores e investidores em seus próprios países.

\section{À guisa de conclusão: a África para os africanos}

Mas não se traça o futuro da África apenas de fora para dentro. Os africanos estão reivindicando e construindo autonomia decisória. Buscam soluçōes nacionais para seus desafios na área social e da cidadania. O controle do Estado e sua orientação para o crescimento econômico e o desenvolvimento sustentável são a boa novidade no continente.

Tornaram-se os líderes africanos refratários à noção de "fim do Estado" e de "governança global" vendidas para a África como solução mágica nos tempos de 
encantamento liberal generalizado, embora em menor grau do que se passou na América Latina nos anos $1990 .{ }^{43}$ Querem falar de transição de modelo para uma forma mais logística de construção do desenvolvimento, com democracia e mais inclusão social. Passaram a operar em novas bases conceituais no pós-Guerra Fria e ante a crise geral do internacionalismo liberal.

O encerramento do grande ciclo dos conflitos abertos e militarizados internos é exemplo dessa vontade política nova de renascer e orientar as energias para projetos mais produtivos. Engajaram-se nos programas voltados para as metas do milênio e querem modificar os indicadores sociais previstos para serem alcançados em 2015. Mas o querem fazer a partir de suas realidades e possibilidades, em parceria horizontal e não mais vertical, com os velhos e novos parceiros da África.

Administrar, de dentro para fora, as ambiçōes internacionais geradas pela "nova partilha africana" posta em marcha pelos planos estratégicos chineses e norte-americanos, mas também em alguma medida do Brasil também, exigirá dos africanos uma noção de domesticação, pela via do fortalecimento do Estado democrático e da responsabilidade fiscal e macroeconômica mais ampla, das tendência malévolas que caminham juntas com a ambição política dos Estados fortes que se organizaram para a nova corrida para a África.

Há, nesse sentido, um ambiente mais positivo. A mais importante iniciativa nesse sentido, emblemática da autoconfiança que se espraia no seio da inteligência política do continente, foi o lançamento da Nova Parceria para o Desenvolvimento Africano (Nepad), em 2001. Ao reivindicarem a capacidade de construção do seu futuro, as lideranças africanas estão atraindo para si a responsabilidade de superação do grau marginal de inserção ao qual o continente foi submetido na década de 1990. Buscar um lugar mais altivo, menos subsidiário na globalização assimétrica atual, é o argumento central do contorno do desenho estratégico que a Nepad significa.

A Nepad não foi feita de fora para dentro da África. Nem é onírico como o Plano de Lagos de 1980 ou limitado como o Programa Africano de Recuperação Econômica de 1986. A Nepad tem caráter inédito, abrangente, social e cidadão, como o Plano Marshall foi para a reedificação da Europa depois da guerra. A metáfora é útil pois Nepad significa "African leadership and African ownership".

$\mathrm{O}$ texto de lançamento fala por si, ao situar a plataforma conceitual no qual a Nepad poderá florescer:

A África pós-colonial herdou Estados fracos e economia disfuncionais que foram agravados ainda por uma liderança fraca, pela corrupção e má-governança em muitos países. Esses dois fatores, conjugados às divisōes causadas pela Guerra Fria, minaram o desenvolvimento de governos responsáveis em todo o continente. ${ }^{44}$

43 Ver, nesse aspecto, a proposição conceitual de Amado Luiz Cervo relativa à noção de Estado logístico, recentemente apresentado no seu novo livro: Amado L. Cervo, Inserção internacional: a formação dos conceitos brasileiros. São Paulo: Editora Saraiva, 2008, parte I: "Conceitos, transição e paradigmas", p. 7-91

44 NEPAD, documento oficial de lançamento, 2001, parágrafo 22. 
O reconhecimento de que o Estado tem um papel central no desempenho do crescimento, no desenvolvimento sustentável e na implantação de programas de redução de pobreza, anotados pelos chefes de Estado na África de 2001 é ainda um sonho. Mas a dimensão utópica das novas vontades expressadas pelos africanos move a vida deles para uma nova agenda política da qual a África não poderá mais se afastar.

O Brasil, que se lança novamente para a África, por meio dos movimentos dinâmicos de sua política exterior e de uma pauta comercial de produtos diversificados e que evolui percentualmente para já representar cerca de $6 \%$ das trocas internacionais do Brasil, tem possibilidades importantes de ocupar a brecha africana. Aproveitar a dinâmica do renascimento africano e da autoconfiança que emerge lá para propor diálogo de interesses mútuos e valores abrangentes para a nova geografia política internacional é agenda convidativa para a fronteira atlântica do Brasil. Otimismo cauteloso deve guiar o Brasil pois há sempre chance, aqui como na África, de reverter o ciclo de retração e desespero em favor do avanço cidadão e da esperança de uma África muito melhor ao final do século XXI.

Recebido em 15 de janeiro de 2008 Aprovado em 15 de junho de 2008

\section{Resumo}

No artigo se propõem novos conceitos acerca do lugar da África na ordem internacional que se desenha no início do século XXI. O avanço gradual do processo de democratização dos Estados nacionais, a performance econômica satisfatória associado ao crescimento econômico generalizado no continente, bem como certa elevação de confiança política das elites, vêm contribuindo para o fortalecimento da capacidade decisória dos governantes no seio das opções disponíveis no sistema internacional que se desenha. O caso de Moçambique é utilizado para justificar o argumento central do artigo.

\section{Abstract}

This article sets out to study new concepts about the Africa's role in the international order, which has been designed in the beginning of the 21 st century. The national states' gradual expansion of democratization process, the satisfactory economic performance associated with the continent's generalized economic development, as well as the growth of political trust by the elites, are factors that have been contributing to strengthen the ruling body's decision skill in to the international system that are being designed. Mozambique's case justifies this article's discussion.

Palavras-chave: África, política regional Africana, Moçambique.

Key words: Africa, African regional politics, Mozambique. 